\title{
A Review on the Present Condition of Histrionic Personality Disorder
}

\author{
Octav Sorin Candel
}

\begin{abstract}
Octav Sorin Candel - PhD student, Alexandru Ioan Cuza University, Faculty of Psychology and Educational Sciences, Toma Cozma Street 3, Iași, 700554
\end{abstract}

\begin{abstract}
Histrionic personality disorder (HPD) firstly appeared in DSM II under the name of hysterical personality disorder. It is characterized by exhibitionist behavior, constant attention seeking, rapidly shifting emotions and high suggestibility. Although its current name firstly appeared in the third edition of DSM, little research has been made specifically on this disorder. Low prevalence and high comorbidity with other personality disorders might act as causes for the general lack of interest in this disorder. The presents study offers a multifaceted perspective on HPD, aiming at discussing its historical roots, some of the most important theories that explain its causes, its prevalence and the ways to assess HPD. In addition, its second aim was to present the most important correlates of HPD. Although narrow, previous research offers some support for maintaining HPD as a personality disorder, contrary to some opinions that consider it should be replaced or eliminated from DSM. In conclusion, this paper highlights the current opinions on HPD and offers a look at its implication in the domain of mental health.
\end{abstract}

\section{KEYWORDS:}

Personality disorder, histrionic, review

\section{INTRODUCTION}

The histrionic personality disorder (HPD) is part of the cluster $\mathrm{B}$ of personality disorders (PDs) (the other PDs present in this cluster being the antisocial, borderline and narcissistic disorders). These disorders are specific to people who demonstrate a dramatic, emotional and unpredictable behavior. From a theoretical point of view, the histrionic disorder was introduced for the first time in DSM III, replacing the former hysterical disorder from the DSM II $(1,2)$. The histrionic personality disorder is characterized by a seductive, overly dramatic and emotionally empty behavior. People suffering from this disorder are described as always wanting to be in the spotlight, being seductive, even provocative, expressing emotions in a theatrical way but with little to no interest in the emotional state of those around them. Such people are admired at first but have great difficulty in maintaining relationships with others due to their behavior.

According to DSM V, the disorder can be diagnosed if a person suffers from five (or more) of the following symptoms: (a) feeling uncomfortable when not in the spotlight; (b) 
social interactions characterized by seductive or sexually challenging behavior; (c) an emotional life characterized by frequent changes, (d) using physical appearance to attract attention; (e) a style of speech designed to impress but lacking content; (f) theatrical, dramatic expression of emotional experiences; (g) high suggestiveness (the person is easily influenced by others); (h) the person considers many relationships to be more intimate than they really are. These must occur during adulthood, in diverse contexts such as family or work (3). The disorder from the ICD 10 is defined in a similar way, though it adds an exaggeration of events such as emotional expression, self-absorption, and a disregard to the others (4). On the other hand, the new ICD 11 classification abolishes the old categorical style and presents a single, continuous personality disorder, which ranges from mild to moderate to severe (5).

If from the point of view of DSM V authors, this disorder is always of a pathological nature, other authors consider that there are also persons characterized by a nonpathological form, which they call the histrionic presentation style (6). This is a form of impression management and consists of interpreting a role, creating a dramatic situation that put the person in a positive light. However, exaggeration of such behaviors can also act to the detriment of the individual by changing the perception of those around them (6).

The definition offered by the authors of DSM $\mathrm{V}$ is not the only one used by specialists. According to the theory of the CognitiveAffective Processing System (CAPS), personality disorders can also be described as non-adaptive schemes caused by some situational stimuli $(7,8)$. For example, manifestations specific to the histrionic disorder are triggered by situations involving intimacy with parental figures. The difficulties that histrionics have in establishing close relationships may stem from their tendency to consider relationships as more intimate than they are in reality, which results in negative emotions. In turn, they can come from negative relationships with parents. Once enabled, the schemas may signal a possible danger that causes the person to be more careful about the ways to stay safe, but also vigilant over the potentially endangering individuals. Transposed into interpersonal contexts, the reactivity to negative stimuli can be perceived as a tiresome manifestation and thus it lessens the partner's desire to increase intimacy. In addition, those who suffer from HPD may refuse very intimate relationships to avoid potential negative stimuli (7). Other cognitive models suggest that maladaptive schemas are responsible for the development of personality disorders (9). Also, a combination of maladaptive schemas can explain the variance in PDs. Some authors consider that approval-seeking, impulsive, undisciplined and abandoned child schema modes are responsible for the development of HPD (10). Also of notice is that the therapeutic intervention based on the schema modes is effective in reducing the symptoms of HPD (11).

Finally, other authors propose that personality disorders are exaggerated manifestations of normal personality characteristics. To support this theory, each disorder can be based on a continuum that goes from the normal characteristics (proposed by the Five Factor Model) to the pathological ones. Thus, Lynam and Widiger even proposed a prototype of the histrionic personality (12). It is characterized by (a) low self-awareness, high impulsivity (facet of neuroticism) (b) sociability, activity, search for challenges, high positive emotions (facet of the extraversion) (c) fantasy, emotions and high actions (facet of openness) (d) high trust (facet of agreeableness) (e) selfdiscipline and low deliberation (facet of conscientiousness). Kaurin, Sauerberger, and Funder (13) offer further proof of the associations between HPD and FFM traits. Their results show that people with HPD also show high scores in Extraversion and Conscientiousness. Furthermore, the acquaintances of persons with HPD could describe their behaviors as being more exaggerated in expressing emotions, socially dominance, and cheerfulness.

From a historical perspective, the term histrionic follows the term hysterical, and it appeared for the first time in DSM II (14). However, the term hysteria had an extremely 
(1)

widespread in the epoch, yet it defined different manifestations (today, the hysterical disorder was replaced by the conversion) and made strong references to sexuality. In DSM II, the hysterical personality was described as emotional instability, exaggerated reactivity, immaturity, attention-seeking behaviors, dramatization, selfishness, vanity, and addiction. As can be seen, however, few features have been retained in DSM V. Also relevant for this historical perspective is the idea the HPD is linked to Galen's choleric type, which together with sanguine, phlegmatic, and melancholic, represents a development of the Hippocratic four humours theory $(15,16)$.

\section{PREVALENCE OF HPD}

Previous studies show a varying prevalence of HPD. It is important to differentiate between the disorder's prevalence in the general population and the prevalence in psychiatric population, but in general, the rates largely variate even within these populations. Bakkevig and Karterud show that in the general population, the prevalence of HPD varies between $3.2 \%$ and $0.0 \%$ for NothAmerican samples and between $2.0 \%$ and 0.0 $\%$ in European samples (17-21). In psychiatric samples, the prevalence was as high as $6.0 \%$ and as low as $1.1 \%(22,23)$. In this case, the highest prevalence was obtained using the ICD 10 while the lowest one was obtained using the DSV IV criteria $(4,24)$. In a more recent meta-analysis based on the results from seven samples, the prevalence was $0.83 \%$ (25). However, after the elimination of one problematic study, the rate dropped to $0.36 \%$. In terms of gender, some authors consider that the HPD is a more feminine disorder (26). However, a review found inconclusive results showing equal risk among genders to develop HPD (27). An interesting remark was made by Bakkevig and Karterud, who consider that HPD is more female-specific, while Narcissistic PD is more specific to males (17). With the two PDs sharing many common traits, the authors proposed that HPD could become a sub-type for the NPD.

\section{ASSESSMENT OF HPD}

There are four main methods of personality assessment that can be used to measure HPD, each one of them with its advantages and disadvantages (28). Unstructured and semistructured interviews are preferred in clinical practice and research. The first option is easier to apply but is far more unreliable, while the second one is more superficial but also more valid and reliable (28). SCID-II is a structured interview that is used in this field (29). Another recommended approach is the use of self-reported interviews. These are less time-consuming and more reliable, comprehensive and usually supported by important research that has shown their value. However, self-reported measures are more prone to biases caused by self-presentation (28). Some of the most important selfassessment instruments for the study of the PDs are the MMPI (Minnesota Multiphasic Personality Inventory-2) or the PDQ -IV (Personality Diagnostic Questionnaire-IV) $(30,31)$. More recently, instruments using the FFM (Five-Factor Model of personality) have been used to measure personality disorder (32). In addition, in order to address the selfreport issues, the specialist can use tests that are based on the assessment made by those who are close to the person or even based on their own history with the patient (28). SWAP-200 (Shedler-Westen Assessment Procedure) is an instrument that is based on the specialist's assessment of the clinical symptoms shown by the patient (33). Finally, the fourth method of assessment is the use of projective techniques, although their empirical support is limited (28).

Although HPD can be measured by a general questionnaire that assesses a large number of mental problems, there is almost no questionnaire developed specifically for this disorder. The author found only one such instrument, the Brief Histrionic Personality Scale (34). This instrument contains 11 items and has good psychometric properties, but given its recent development, further tests are necessary in order to demonstrate its validity and reliability across different samples.

Correlates of HPD

Firstly, HPD shows important comorbidities with borderline, narcissistic and dependent 


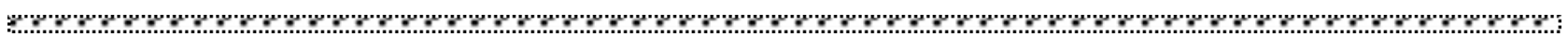

personality disorders (17). It is also associated with substance use disorders. Individuals with HPD have a higher risk of developing alcohol use disorder, alcohol abuse, and alcohol dependence and the scores at HPD were correlated with the scores for alcohol disorder and dependence $(35,36)$. The correlations between HPD and drug abuse, disorder and dependence were also significant and positive, while the individuals with HPD have the second-highest risk of developing drugrelated disorders after those diagnosed with anti-social personality disorder $(35,36)$. In general, cluster B personality disorders were associated with internet addiction, which confirms the fact that histrionic individuals like and search for new ways in which they can present themselves (an opportunity that might be provided by the online social networks) (37). In addition, histrionic PD is associated with a higher number of selfies (38).

HPD is significantly associated with more bullying behavior in both adolescent and adult samples $(39,40)$. However, its prevalence in a sample composed of sexual perpetrators was very low (only 3 out of 76 investigated individuals) (41).

Histrionic patients have more alexithymic features compared to a healthy control group (42). For women, previous studies reported higher comorbidity between HPD and ADHD symptoms (43). In a longitudinal study, HPD was related with higher rates of major depression disorder at a subsequent time point (MDD; although the co-occurrence of HDD and MDD is reduced in cross-sectional studies), but in cross-sectional research, HPD was not related with higher suicide risk (44, 45). Nevertheless, HPD has a high prevalence among patients diagnosed with Anorexia Nervosa (especially in the binge/purge subtype - $10 \%)$ and among those with Bulimia Nervosa (20\%) (46). In addition, when faced with making a financial offer towards a histrionic partner, the participants in some experiments made lower offers and allocations towards histrionic individuals (47).

However, HPD is also associated with some positive outcomes. Histrionic individuals seem to be aware of their negative emotions; the PD is associated with less impulsivity and better self-reported emotional regulation (48). A review of the associations between PDs and sexual behavior reported that while histrionic women were involved in more divorces, histrionic males reported better sexual functioning (49). Finally, histrionic PD might have some beneficial effects in reducing the levels of loneliness and social anxiety (50).

\section{CONCLUSIONS}

Over time, histrionic personality disorder has undergone some changes in both terminology and definition. However, current authors tend to view the DSM V definition as the best. That being said, I believe that the classic definition of the Diagnostic Manual and Statistical Classification of Mental Disorders can be kept, but it should be noted that there is a continuum that goes from a normal, nonpathological trait to a pathological nature.

Unlike other personality disorders, fewer authors have been interested in studying the histrionic personality disorder. This is particularly noticeable in the case of measurement scales, where there is only a scale developed in recent years and where the more general scales for personality disorders are used. The lack of measuring instruments and the very small number of studies focusing only on this disorder can be explained by a conceptual overlap of this disorder with others, especially with narcissistic PD, but also by its diagnosis based on behaviors that may be specific to many other disorders. Finally, the low prevalence in both general and patient populations (both around 1\%) and high comorbidity can make the disorder appear less interesting. However, the histrionic disorder correlates with certain anti-social behaviors (bullying, drug or alcohol consumption), and with depression and eating disorders. From this point of view, its study in relation to other such variables could provide important clues about the ways of preventing such behaviors in school, organizational context or more generally speaking, in society. 


\section{ACKNOWLEDGEMENTS AND DISCLOSURES}

The authors declare that they have no potential conflicts of interest to disclose

\section{REFERENCES}

1. American Psychiatric Association. Diagnostic and Statistical Manual of Mental Disorders. 3th ed. Washington D.C.: 1980

2. American Psychiatric Association. Diagnostic and Statistical Manual of Mental Disorders. 2nd ed. Washington D.C.: 1968

3. American Psychiatric Association. Diagnostic and Statistical Manual of Mental Disorders. 5th ed. Washington D.C.: 2013

4. WHO. International Classifi cation of Diseases, 10th Revision. Mental and Behavioural Disorders. Geneva: World Health Organization, 1992.

5. WHO. International Classifi cation of Diseases, 10th Revision. Mental and Behavioural Disorders. Geneva: World Health Organization, 2018.

6. Renner K, Enz S, Friedel H, Merzbacher G, Laux L. Doing as if: The histrionic self-presentation style. J Res Pers. 2008;42(5):1303-1322. doi:10.1016/j.jrp.2008.04.005

7. Rahamim O, Meiran N, Ostro S, Shahar G. Individuals with histrionic personality disorder features categorize disliked persons as negative following intimacy induction : A state trait interaction analysis. Pers Individ Dif. 2012;52(7):788-793. doi:10.1016/j.paid.2012.01.006

8. Eaton N, South S, Krueger R. The Cognitive-Affective Processing System (CAPS) approach to personality and the concept of personality disorder: Integrating clinical and social-cognitive research. J Res Pers. 2009;43(2):208-217. doi:10.1016/j.jrp.2009.01.016

9. Dadashzadeh H, Hekmati I, Gholizade H, Abdi R. Schema modes in cluster B personality disorders. Archives of Psychiatry and Psychotherapy. 2016;18(2):22-28. doi:10.12740/app/63535

10. Johnston C, Dorahy M, Courtney D, Bayles T, O'Kane M. Dysfunctional schema modes, childhood trauma and dissociation in borderline personality disorder. J Behav Ther Exp Psychiatry. 2009;40(2):248-255. doi:10.1016/j.jbtep.2008.12.002

11. Bamelis L, Evers S, Arntz A. Design of a multicentered randomized controlled trial on the clinical and cost effectiveness of schema therapy for personality disorders. BMC Public Health. 2012;12(1). doi:10.1186/1471-2458-1275

12. Lynam D, Widiger T. Using the five-factor model to represent the DSM-IV personality disorders: An expert consensus approach. J Abnorm Psychol. 2001;110(3):401-412. doi:10.1037//0021-843x.110.3.401

13. Kaurin A, Sauerberger K, Funder D. Associations between informant ratings of personality disorder traits, selfreports of personality, and directly observed behavior. J Pers. 2018;86(6):1078-1101. doi:10.1111/jopy.12376

14. Novais F, Araújo A, Godinho P. Historical roots of histrionic personality disorder. Front Psychol. $2015 ; 6$. doi:10.3389/fpsyg.2015.01463

15. Tyrer P, Reed G, Crawford M. Classification, assessment, prevalence, and effect of personality disorder. The Lancet. 2015;385(9969):717-726. doi:10.1016/s0140-6736(14)61995-4

16. Kagan J. Galen's prophecy: temperament in human nature. New York: Basic Books, 1998.

17. Bakkevig J, Karterud S. Is the Diagnostic and Statistical Manual of Mental Disorders, Fourth Edition, histrionic personality disorder category a valid construct?. Compr Psychiatry. 2010;51(5):462-470. doi:10.1016/j.comppsych.2009.11.009

18. Black DW, Noyes R, Pfohl B, Goldstein RB, Blum N. Personality disorder in obsessive-compulsive volunteers, well comparison subjects, and their third-degree relatives. Am J Psychiatry 1993;150:1226-32.

19. LenzenwegerMF, LorangerAW,KorfineL, NeffC.Detecting personality disorders in a nonclinical population: application of a 2-stage procedure for case identification. Arch Gen Psychiatry 1997;54:345-51

20. Coid J, Yang M, Tyrer P, Roberts A, Ullrich S. Prevalence and correlates of personality disorder in $\mathrm{Great} \mathrm{Britain}$. $\mathrm{Br}$ J Psychiatry 2006;188(5):423-31

21. Torgersen S, Kringlen E, Cramer V. The prevalence of personality disorders in a community sample. Arch Gen Psychiatry 2001;58: 590-6.

22. Keown P, Holloway F, Kuipers E. The prevalence of personality disorders, psychotic disorders and affective disorders amongst the patients seen by a community mental health team in London. Soc Psychiatry Psychiatr Epidemiol 2002;37(5):225-9.

23. Zimmerman M, Rothschild L, Chelminski I. The prevalence of DSMIV personality disorders in psychiatric outpatients. Am J Psychiatry 2005;162(10):1911-8.

24. American Psychiatric Association. Diagnostic and Statistical Manual of Mental Disorders. 4th ed. Washington D.C.: 1995

25. Volkert J, Gablonski T, Rabung S. Prevalence of personality disorders in the general adult population in Western countries: systematic review and meta-analysis. The British Journal of Psychiatry. 2018;213(6):709-715. doi:10.1192/bjp.2018.202

26. Corbitt EM, Widiger TA. Sex differences among the personality disorders: an exploration of the data. Fal, 1995. Clin Psychol Sci Pract. 1995;2(3). 


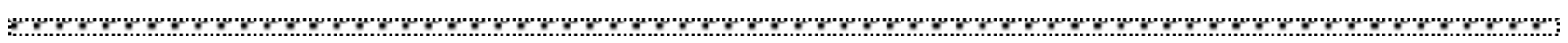
27. Schulte Holthausen B, Habel U. Sex Differences in Personality Disorders. Curr Psychiatry Rep. 2018;20(12). doi:10.1007/s11920-018-0975-y

28. Widiger T, Bornstein R. Histrionic, narcissistic, and dependent personality disorders. In: Sutker P, Adams H, ed. Comprehensive Handbook Of Psychopathology. 3rd ed. Boston: Springer; 2002:509-531.

29. First M, Gibbon M, Spitzer R, Williams J, Benjamin L. Structured Clinical Interview For DSM-IV Axis II Personality Disorders, SCID-II. Washington, DC: American Psychiatric Press; 1997.

30. Morey L, Waugh M, Blashfield R. MMPI Scales for DSM-III Personality Disorders: Their Derivation and Correlates. J Pers Assess. 1985;49(3):245-251. doi:10.1207/s15327752jpa4903_5

31. Hyler S. Personality Diagnostic Questionnaire-4. New York; 1994.

32. Trull T, Widiger T. Dimensional models of personality: the five-factor model and the DSM-5. Dialogues Clin Neurosci. 2013;15(2):135-146.

33. Shedler J, Westen D. The Shedler-Westen Assessment Procedure (SWAP): Making Personality Diagnosis Clinically Meaningful. J Pers Assess. 2007;89(1):41-55. doi:10.1080/00223890701357092

34. Ferguson C, Negy C. Development of a brief screening questionnaire for histrionic personality symptoms. Pers Individ Dif. 2014;66:124-127. doi:10.1016/j.paid.2014.02.029

36. Grant, B., Stinson, F., Dawson, D., Chou, S., Ruan, W., \& Pickering, R. (2004). Co-occurrence of 12-Month Alcohol and Drug Use Disorders and PersonalityDisorders in the United States. Arch Gen Psychiatry, 61(4), 361. http://dx.doi.org/10.1001/archpsyc.61.4.361

36. Trull T, Waudby C, Sher K. Alcohol, Tobacco, and Drug Use Disorders and Personality Disorder Symptoms. Exp Clin Psychopharmacol. 2004;12(1):65-75. doi:10.1037/1064-1297.12.1.65

37. Zadra S, Bischof G, Besser B et al. The association between Internet addiction and personality disorders in a general population-based sample. J Behav Addict. 2016;5(4):691-699. doi:10.1556/2006.5.2016.086

38. Sorokowski P, Sorokowska A, Frackowiak T, Karwowski M, Rusicka I, Oleszkiewicz A. Sex differences in online selfie posting behaviors predict histrionic personality scores among men but not women. Comput Human Behav. 2016;59:368-373. doi:10.1016/j.chb.2016.02.033

39. Coolidge F, DenBoer J, Segal D. Personality and neuropsychological correlates of bullying behavior. Pers Individ Dif. 2004;36(7):1559-1569. doi:10.1016/j.paid.2003.06.005

40. Vaughn M, Fu Q, Bender K et al. Psychiatric Correlates of Bullying in the United States: Findings from a National Sample. Psychiatric Quarterly. 2010;81(3):183-195. doi:10.1007/s11126-010-9128-0

41. Kanyanya, I., Othieno, C., \& Ndetei, D. (2008). Psychiatric morbidity among convicted male sex offenders at Kamiti Prison, Kenya. E Af Med Jrnl, 84(4). http://dx.doi.org/10.4314/eamj.v84i4.9518

42. Ritzl A, Csukly G, Balázs K, Égerházi A. Facial emotion recognition deficits and alexithymia in borderline, narcissistic, and histrionic personality disorders. Psychiatry Res. 2018;270:154-159. doi:10.1016/j.psychres.2018.09.017

43. Edvinsson D, Lindström E, Bingefors K, Lewander T, Ekselius L. Gender differences of axis I and II comorbidity in subjects diagnosed with attention-deficit hyperactivity disorder as adults. Acta Neuropsychiatr. 2013;25(3):165-74.

44. van der Wal S, Bienvenu O, Romanoski A, Eaton W, Nestadt G, Samuels J. Longitudinal relationships between personality disorder dimensions and depression in a community sample. Neurology, Psychiatry and Brain Research. 2018;30:56-61. doi:10.1016/j.npbr.2018.05.005

45. Szücs A, Szanto K, Aubry J, Dombrovski A. Personality and Suicidal Behavior in Old Age: A Systematic Literature Review. Front Psychiatry. 2018;9. doi:10.3389/fpsyt.2018.00128

46. Pisetsky E, Utzinger L, Wonderlich S. Personality Disorders as Comorbidities in Eating Disorders. In: Wade T, ed. Encyclopedia Of Feeding And Eating Disorders. ; 2017:1-4.

47. Reed L, Harrison E, Best C, Hooley J. Bargaining with characters: How personality pathology affects behavior in the ultimatum and dictator games. Pers Individ Dif. 2019;140:65-69. doi:10.1016/j.paid.2018.05.035

48. Collazzoni A, Ciocca G, Limoncin E et al. Mating Strategies and Sexual Functioning in Personality Disorders: A Comprehensive Review of Literature. Sex Med Rev. 2017;5(4):414-428. doi:10.1016/j.sxmr.2017.03.009

49. Garofalo C, Velotti P, Callea A et al. Emotion dysregulation, impulsivity and personality disorder traits: A community sample study. Psychiatry Res. 2018;266:186-192. doi:10.1016/j.psychres.2018.05.067

50. Berryman C, Ferguson C, Negy C. Social Media Use and Mental Health among Young Adults. Psychiatric Quarterly. 2017;89(2):307-314. doi:10.1007/s11126-017-9535-6

\section{Correspondence:}

Octav Sorin Candel,

PhD student, Alexandru Ioan Cuza University, Faculty of Psychology and Educational Sciences, Toma Cozma Street 3, Iași, 700554, candel.octav@yahoo.com 